\section{From molecular to vernacular}

\section{S. M. Walters}

The Concise Oxford Dictionary of Botany. Edited by Michael Allaby. Oxford University Press: 1992. Pp. 442. £18.95, \$35 (hbk); £6.99, \$11.95 (pbk).

DICTIONARIES are not to be judged primarily as literary works, but for their coverage and clarity of definition. It is, however, permissible to comment more generally on the preface, for here the aims and intentions of the publishers and the editors are revealed. Michael Allaby's preface is clear, both as to the intended readership - "no longer confined to a minority of specialists" - and style - "a compromise between the two extremes" of encyclopaedia and definitional dictionary. As the proof of the pudding is in the eating, some sampling seems called for.

On the inclusion and definition of individual families and genera, the dictionary scores highly. Of course, selection is a problem, and it would be easy to criticize particular inclusions (35 lines devoted to Haloragidaceae and the genus Haloragis may seem excessive to some), but the coverage of all plant groups, including the Lower Plants (not, incidentally, to be found as an entry) seems fairly generous. What of vernacular names? Here lies an insuperable difficulty, although any policy that excluded, for example, 'lychee', 'pink' or 'shield fern' would be unfortunate. But what about 'campion' and 'eyebright', both widely used English names capable of reasonable definition, but not included?

A more serious test is the coverage of cell and molecular biology. Whether we like it or not, most students of botany are now being taught in departments of plant science or biology, and are exposed to DNA, RNA and the like from the start. Acronyms abound, and 'cistrons', 'codons' and other conceptual novitates proliferate. Dictionaries of botany would not sell if they excluded these new terms, but an old reviewer like myself might reasonably ask where this process ends.

A very different area to cover is biological conservation and concern for the environment. Many younger botanists, who might reasonably become users of this dictionary, 'think globally' in a way their predecessors could not, and terms such as 'biodiversity' and 'biosphere' must find their place here. Even the 'Gaian hypothesis' is included, with a rather careful, noncommittal definition.

Zoological dominance is reflected in the definitions of several terms of biosystematic interest, including the crucial definition of the species itself. It is, pace Allaby and the Oxford University Press, just not true that: "In taxonomy, it is applied to one or more groups (populations) of individuals that can interbreed within the group, but that cannot exchange genes with other groups...". Neither zoologists nor botanists actually operate the taxonomic game on this definition, although zoologists generally seem to pretend that they do. Botanists, in my experience, are more realistic: for every taxonomic species for which there is any substantial body of relevant biosystematic information, there are a hundred for which the morphological criteria are the only ones. Why do we

\title{
M-words and the brain
}

\section{Susan Greenfield}

The Making of Memory: From Molecules to Mind. By Steven Rose. Bantam: 1992. Pp. 355. £16.99.

M-WORDS are particularly prevalent in neuroscience titles because of the catchy oxymorons and alliteration that can be achieved with permutations of 'molecules', 'mind', 'matter', 'make', 'machinery/mechanics' and the like. Steven Rose's book follows in this tradition and introduces a further M-word to savour, memory. There are three central themes: "To chronicle an adventure in research, illustrate the nature of doing science and reflect on the theory of mind".

Rose's account of his own personal adventure into the biochemical basis of memory traces the way in which collective scientific opinion went off the rails, driven by the assumption that memories could be attributed to molecules per se. And thus we learn the importance of neuronal organization and canter through the familiar reductionist territory of Aplysia and hippocampal longterm potentiation in the sobering light of their questionable physiological relevance to real-life long-term memory. Unfortunately, the more enduring, and thus highly relevant, changes induced by kindling are not discussed at all. Rose moves straight on to describe his own work in seminar-level detail and then turns to recounting how a facile interpretation almost prevented him from seeing a deeper truth. Remarkably, this account of 'pure' science is far from indigestible for the general reader, as Rose is consummate at side-stepping or translating the idiosyncratic terminology and concepts of biochemistry and physiology. The plethora of human interest continue to delude ourselves? The definition of 'deme' - a term originally defined by two botanists - is sufficient to make John Gilmour (one of the two) cry out from the grave, for what is offered as a definition is properly applied to 'gamodeme', and is a zoological aberration.

Dictionaries, finally, are places where the compiler can have a little quiet fun. Turn to page 238 , and the running head is "Loppium et chippium". Look down the page and sure enough there it is, coolly defined as "the bark, branches, rotten wood, and leaves from a felled tree". One lives and learns!

S. M. Walters is at Inland Close, 46 Mill Way, Grantchester, Cambridge CB3 9NB, UK. anecdotes and the highly personalized narrative more than compensate for the sprinkling of insipid illustrations. The biggest frustration, however, is that the author does not follow up the deeper truth: that the memory for a certain object is distributed in different brain regions. This idea already has an established precedent in the visual system, again not mentioned, and it would have been even more rewarding for the reader for the concept to be set in the general context of the problem of the unifying nature of mind, which is after all within the chosen remit.

The coverage of the day-to-day life of a scientist is highly original and timely. The 'typical' day of a research worker offers a vivid alternative to the image of the white-coated zombie. But the narrative peters out somewhat after a detailed account of the experiments in the morning, just when the reader has acquired a taste for knowing more about the personalities involved and how they interact. Similarly, the journalistic potential in describing conferences and the trials of publication is far from fully tapped. This type of exposé of the human face of scientific research could arguably be a book in itself, especially if ethical considerations are also included. Rose should be strongly commended for confronting the issue of vivisection and discussing it in a frank and open way: he describes exactly what he does to chicks and then offers his reasons. For this initiative he might be forgiven for not telling us what happens in his laboratory in the afternoon.

The third theme relates to mind, a subject that few would deny is now a growth industry. Rose's justification for taking memory as both a title and his 